\title{
Characteristics of Hospital Acquired Pressure Ulcer and Factors Affecting Its Development: A Retrospective Study
}

\author{
Hatan Mortada ${ }^{1}$, Nader Malatani ${ }^{2}$, Basim A. Awan ${ }^{3}$, Hattan Aljaaly ${ }^{3}$ \\ 1. Division of Plastic Surgery, Department of Surgery, College of Medicine, King Saud University, Riyadh, SAU 2. \\ Department of Emergency Medicine, King Fahad General Hospital, Jeddah, SAU 3. Division of Plastic Surgery, \\ Department of Surgery, Faculty of Medicine, King Abdulaziz University, Jeddah, SAU
}

Corresponding author: Hattan Aljaaly, hattanaljaaly@gmail.com

\section{Abstract}

\section{Background}

Worldwide, pressure ulcers (PUs) have been implicated in costing billions annually, with 60,000 deaths out of 2.5 million hospitalized patients resulting from complications related to PU. The prevention of PU reduces the incidence of other illnesses, decreases the financial costs, and improves the quality of life for patients. We aimed to identify the most influential factors that increased the risk of developing PUs among hospitalized patients at a university hospital according to the Waterlow scale.

\section{Methods}

Data were collected retrospectively from patients who developed PUs between January 2016 and December 2018 at King Abdulaziz University Hospital, Jeddah, Saudi Arabia, and were evaluated using the Waterlow PU risk assessment tool. The analysis was performed using the Statistical Package for Social Science (SPSS), version 23.0 (IBM, Armonk, NY).

\section{Results}

A total of 272 cases were included in this study. The highest number of cases $(n=83,30.5 \%)$ belonged to the age group of 50 to 64 years. The majority of patients had stage 2 PUs $(165,60.7 \%)$. The most frequent location of PU was the "back" (97, 35.7\%). A history of undergoing major surgery was significantly associated with a higher stage of PU $(p=0.040)$. The mean Waterlow PU score for all cases was $27.19 \pm 13.143$. There was a moderate positive correlation between the neurological deficit score and the Waterlow PU score (correlation coefficient: $0.447, \mathrm{p}<0.001$ ). Multinomial logistic regression analysis revealed that increasing age is a significant predictive factor for developing higher stages of PUs $(p=0.046)$.

\section{Conclusion}

Review began 11/15/2020 Review ended 12/03/2020 Published 12/09/2020

\section{○ Copyright 2020}

Mortada et al. This is an open access article distributed under the terms of the Creative Commons Attribution License CC-BY 4.0., which permits unrestricted use, distribution, and reproduction in any medium, provided the original author and source are credited.
Major surgery, neurological deficit, low hemoglobin level, and increasing age were strong predictors for developing higher stages of PU. Therefore, healthcare contributors should consider these risks when applying a comprehensive PU management plan.

Categories: Plastic Surgery, Preventive Medicine, Quality Improvement

Keywords: pressure injury, hospital acquired, risk factors, characteristics, age, saudi arabia, wound

\section{Introduction}

Pressure ulcer (PU) is a common medical problem that affects patients in healthcare settings worldwide [1]. A PU is also known as bedsore, pressure injury, pressure sore, or decubitus ulcer, and its defined as damage that is localized to the skin or/and underlying soft tissue, be it linked to a medical device or skin over a bony prominence. Pressure injuries may occur as an intact skin or as an open painful or painless ulcer, resulting from prolonged or/and intense pressure in combination with shear [2]. Across the Middle East, the prevalence of a PU is estimated to be 7-44.4\% [3,4]. Previous research has been conducted in a 144-bed governmental hospital in Saudi Arabia, and they have found that the prevalence of hospital-acquired PU was $7.5 \%[5]$.

In fact, the prevalence of PU also defers long-term care, acute care, home care, and rehabilitative care by healthcare setting [3]. Patients in the intensive care unit (ICU) have a high risk of developing PU, with an estimated incidence between 3.3\% and 52.9\% [6,7]. Globally, PU has been implicated in \$11 billion in costs annually, and in the United States, 60,000 deaths out of 2.5 million hospitalized patients have resulted from complications related to PU, each year [8]. The cost to establish PU prevention to our patients at risk can tremendously affect the healthcare systems' resources [9]. Prevention of PU by involving the patient and their families plays a major role in reducing the incidence of other illnesses, decrease the financial costs, 
and improve the quality of life for our patients [10-12]. Preventing PUs from occurrence is the key principles in its management. The multidisciplinary managing team should not only focus on the wound but also take a broad approach that needs the patient and their family [13]. PU represents an interplay of a combination of factors contributing to its development from both the patient and the environment [14]. According to various prospective studies, factors such as low serum albumin level, age, mobilization, exercise, diabetes intake, and skin PU status have been found to increase the risk of developing PU $[15,16]$. However, there has been no single factor that can determine the risk of PU development [17]. Therefore, this observational retrospective study aimed to identify and determine the most influential factors that increase the risk of developing PUs among hospitalized patients at a university hospital according to the Waterlow scale.

\section{Materials And Methods Study design and setting}

We performed a retrospective cohort study targeting patients of both sexes who developed PUs between January 2016 and December 2018 at King Abdulaziz University Hospital (KAUH), Jeddah, Saudi Arabia. In order to better reflect our results, we intended to include all patients who experienced hospital-acquired PUs, were over 18 years of age, were not reported to have PUs prior to admission to KAUH, and were assessed using the Waterlow score throughout hospitalization. A list of the medical record of a number of patients who satisfied the inclusion criteria was obtained.

\section{Data collection sheet}

After reviewing the literature, we formulated a collection sheet to enter the data based on several published ones $[14,17]$. The data were collected retrospectively from the Phoenix (KAUH database) using excel sheets composed of 20 variables, including the patients' demographic characteristics (sex, age, length of stay (LOS), comorbidities, admitted unit), stage and site of the PU, those of the Waterlow PU risk assessment tool (including body mass index (BMI), appetite, mobility, continence, skin type/visual risk areas, special risks/medications, tissue malnutrition, neurological deficit, and major surgery/trauma), and laboratory findings (albumin and hemoglobin levels).

\section{Statistical analysis}

Data were checked for errors and completeness. Descriptive statistics were used to present the baseline characteristics and all PU-related variables. Continuous variables were checked for normality using the Kolmogorov-Smirnov test and Shapiro-Wilk test. Feeding route, mobility status, continence, risk of medications, tissue nutrition, major surgery, and comorbidities were presented for all stages of PU, and the relationship of the former variable to the latter was observed by chi-square test. Correlations between all continuous variables (neurological deficit score, LOS, albumin, hemoglobin, and Waterlow PU score) were assessed using Spearman's rank correlation test. A multinomial logistic regression model was performed by counting the stages of PU as the dependent variable and LOS, albumin level, hemoglobin level, Waterlow PU score, neurological deficit score, sex, comorbidities, and age as independent variables. The analysis was performed using the Statistical Package for Social Science (SPSS), version 23.0 (IBM, Armonk, NY, USA).

\section{Ethics approval and consent to participate}

Patient medical records were obtained after participants' written consent, and the data were collected after we received ethical approval for this study from the Institutional Review Board and the Research Ethics Committee of King Abdulaziz University in Jeddah, Saudi Arabia. (Reference No. 26-18).

\section{Results}

A total of 272 cases were included in this study, of which 145 (53.3\%) were males. The highest number of cases $(n=83,30.5 \%$ ) belonged to the age group of 50 to 64 years (Table 1 ).

\begin{tabular}{|c|c|c|}
\hline Characteristics & $\mathbf{N}$ & $\%$ \\
\hline \multicolumn{3}{|l|}{ Unit } \\
\hline MICU & 68 & 25.0 \\
\hline SICU & 51 & 18.8 \\
\hline ER & 41 & 15.1 \\
\hline FMW & 32 & 11.8 \\
\hline MMW & 14 & 5.1 \\
\hline Gyn & 13 & 4.8 \\
\hline
\end{tabular}




\section{Cureus}

\begin{tabular}{|c|c|c|}
\hline MSW & 11 & 4.0 \\
\hline Others & 42 & 15.4 \\
\hline \multicolumn{3}{|l|}{ Gender } \\
\hline Male & 145 & 53.3 \\
\hline Female & 127 & 46.7 \\
\hline \multicolumn{3}{|l|}{ Age group (years) } \\
\hline $14-49$ & 67 & 24.6 \\
\hline $50-64$ & 83 & 30.5 \\
\hline $65-74$ & 63 & 23.2 \\
\hline $75-80$ & 31 & 11.4 \\
\hline $81+$ & 28 & 10.3 \\
\hline \multicolumn{3}{|l|}{ BMI } \\
\hline Below average $(\mathrm{BMI}<20)$ & 36 & 13.2 \\
\hline Average (BMI 20-24.9) & 122 & 44.9 \\
\hline Above average (BMI 25-29.9) & 55 & 20.2 \\
\hline Obese (BMI >30) & 59 & 21.7 \\
\hline \multicolumn{3}{|l|}{ Feeding } \\
\hline Poor & 48 & 17.6 \\
\hline No/anorexia & 58 & 21.3 \\
\hline Nasogastric tube/fluids only & 93 & 34.2 \\
\hline Average & 73 & 26.8 \\
\hline \multicolumn{3}{|l|}{ Motility } \\
\hline Apathetic (sedated/depressed/reluctant to move) & 15 & 5.5 \\
\hline Bedbound (unconscious/unable to change position/traction) & 143 & 52.6 \\
\hline Chair bound (unable to leave the chair without assistance) & 12 & 4.4 \\
\hline Fully mobile & 45 & 16.5 \\
\hline Restless/fidgety & 8 & 2.9 \\
\hline Restricted (restricted by severe pain or disease) & 49 & 18.0 \\
\hline \multicolumn{3}{|l|}{ Continence } \\
\hline Catheterized with fecal incontinence & 90 & 33.1 \\
\hline Complete/catheterized & 131 & 48.2 \\
\hline Urinary and fecal (double) incontinence & 43 & 15.8 \\
\hline Urine incontinence & 8 & 2.9 \\
\hline \multicolumn{3}{|l|}{ Major surgery } \\
\hline No surgery & 241 & 88.6 \\
\hline On table $>2$ hours (up to 48 hours post-op) & 12 & 4.4 \\
\hline On table $>6$ hours & 13 & 4.8 \\
\hline hopedic below waist/spinal (up to 48 hours post & 6 & 2.2 \\
\hline
\end{tabular}

TABLE 1: Baseline characteristics of all cases $(n=272)$. 


\section{Cureus}

MICU: medical intensive care unit, SICU: surgical intensive care unit, ER: emergency, FMW: female medical ward, MMW: male medical ward, Gyn: gynecology ward, MSW: male surgical ward, BMI: body mass index.

One hundred sixty-five $(60.7 \%, \mathrm{n}=165)$ patients had stage 2 PUs, $57(21 \%)$ had stage four, and $45(16.5 \%)$ had stage one. The most frequent location of PU was the "back" (97, 35.7\%), followed by the "sacral region" (96, 35.3\%). The most common skin type was "dry/itchy" (179, 65.8\%). Only 73 (26.8\%) cases had "normal/average" food intake while others required a nasogastric tube or parenteral nutrition. More than half of the patients were bedbound $(143,52.6 \%)$. Urinary and fecal (double) incontinence was present in eight (2.9\%) cases. The clear majority $(241,88.6 \%)$ did not undergo surgery.

Table 2 presents the distribution of feeding, mobility, continence, risk of medications, tissue malnutrition, major surgery, and comorbidities according to stages of PU. Major surgery was significantly associated with a higher stage of PU $(p=0.040)$.

\begin{tabular}{|c|c|c|c|c|c|}
\hline Variables & Stage $1(\%)$ & Stage $2(\%)$ & Stage $3(\%)$ & Stage $4(\%)$ & p-Value \\
\hline \multicolumn{5}{|l|}{ Feeding } & \multirow{5}{*}{0.196} \\
\hline Poor & 15.6 & 17.0 & 20.0 & 21.1 & \\
\hline No/anorexia & 11.1 & 21.2 & 60.0 & 26.3 & \\
\hline Nasogastric tube/fluids only & 44.4 & 35.2 & 20.0 & 24.6 & \\
\hline Average & 28.9 & 26.7 & 0.0 & 28.1 & \\
\hline \multicolumn{6}{|l|}{ Mobility } \\
\hline Fully mobile & 17.8 & 15.8 & 0.0 & 19.3 & \multirow{2}{*}{0.526} \\
\hline Not fully mobile & 82.2 & 84.2 & 100.0 & 80.7 & \\
\hline \multicolumn{5}{|l|}{ Continence } & \multirow{5}{*}{0.941} \\
\hline Catheterized with fecal incontinence & 37.8 & 32.7 & 40.0 & 29.8 & \\
\hline Complete/catheterized & 37.8 & 49.7 & 40.0 & 52.6 & \\
\hline Urinary and fecal (double) incontinence & 20.0 & 15.2 & 20.0 & 14.0 & \\
\hline Urine Incontinence & 4.4 & 2.4 & 0.0 & 3.5 & \\
\hline \multicolumn{5}{|l|}{ Risk of medications } & \multirow{3}{*}{0.988} \\
\hline Yes & 75.6 & 74.5 & 80.0 & 73.7 & \\
\hline No & 24.4 & 25.5 & 20.0 & 26.3 & \\
\hline \multicolumn{5}{|l|}{ Tissue malnutrition } & \multirow{3}{*}{0.764} \\
\hline No & 26.7 & 21.8 & 20.0 & 28.1 & \\
\hline Yes & 73.3 & 78.2 & 80.0 & 71.9 & \\
\hline \multicolumn{5}{|l|}{ Major surgery } & \multirow{3}{*}{0.040} \\
\hline No & 91.1 & 84.8 & 100.0 & 96.5 & \\
\hline Yes & 8.9 & 15.2 & 0.0 & 3.5 & \\
\hline \multicolumn{5}{|l|}{ Comorbidities } & \multirow{3}{*}{0.073} \\
\hline No & 77.8 & 84.8 & 80.0 & 57.9 & \\
\hline Yes & 22.2 & 15.2 & 20.0 & 42.1 & \\
\hline
\end{tabular}

TABLE 2: Distribution of all cases by feeding, mobility, continence, risk of medications, tissue malnutrition, major surgery, and comorbidities by stage of pressure ulcer. 
The mean Waterlow PU score for all cases was $27.19 \pm 13.143$. Table 3 shows the correlation between the continuous variables; a moderate uphill correlation between neurological deficit score and Waterlow PU score was observed (correlation coefficient: $0.447, \mathrm{p}<0.001$ ). Multinomial logistic regression analysis revealed that increasing age was a significant predictive factor for developing higher stages of PUs $(\mathrm{p}=$ 0.046).

\begin{tabular}{|c|c|c|c|c|c|}
\hline Correlation matrix & Neurological deficit score & LOS & Albumin & Hemoglobin & Waterlow PU score \\
\hline \multicolumn{6}{|l|}{ Neurological deficit score } \\
\hline Correlation coefficient & 1.000 & 0.035 & -0.100 & -0.210 & 0.447 \\
\hline $\mathrm{p}$-Value & - & 0.561 & 0.123 & 0.001 & 0.000 \\
\hline \multicolumn{6}{|l|}{ LOS } \\
\hline Correlation coefficient & & 1.000 & -0.092 & -0.125 & -0.015 \\
\hline $\mathrm{p}$-value & & - & 0.156 & 0.040 & 0.804 \\
\hline \multicolumn{6}{|l|}{ Albumin } \\
\hline Correlation coefficient & & & 1.000 & 0.204 & -0.121 \\
\hline$p$-value & & & - & 0.002 & 0.062 \\
\hline \multicolumn{6}{|l|}{ Hemoglobin } \\
\hline Correlation coefficient & & & & 1.000 & -0.223 \\
\hline p-value & & & & - & 0.000 \\
\hline \multicolumn{6}{|l|}{ Waterlow PU score } \\
\hline Correlation coefficient & & & & & 1.000 \\
\hline $\mathrm{p}$-Value & & & & & - \\
\hline
\end{tabular}

TABLE 3: Correlation between neurological deficit score, LOS in hospital, albumin, hemoglobin, and Waterlow PU score.

PU: pressure ulcer, LOS: length of stay.

\section{Discussion}

Overall, 272 patients were involved in this article. The majority of our patients aged from 50 to 64 years (83 cases, $30.5 \%)$. Most of them had two pressure injuries $(165,60.7 \%)$. The "back" was the most common location of the PU (97, 35.7\%). Having a history of undergoing a major surgical procedure was a significant factor associated with a deeper stage of PU $(p=0.04)$. The overall mean of the Waterlow PU score for all the involved cases was $27.19 \pm 13.143$. PU can occur in various settings, at home and in any hospital ward or department. In admitted patients, pressure damage has a prevalence of 3-6\% [18,19]. Meanwhile, the incidence of developing a PU after surgery is $54.8 \%$ [20]. Hence, adequate perception and knowledge regarding PU prevention strategies play a major role in preventing PUs [21]. PU does not only cause a significant economic burden and raise the workload of healthcare providers but also disturbs the patient as it causes pain, and the pain, exudation, and body look disruption have negative effects on the quality of life of the patient and prevent wound healing [22]. Identifying risk factors is the most significant and important method to reduce this burden. Therefore, the goal of this study was to identify and evaluate the most influential factors for the development of PUs among hospital patients according to the Waterlow scale. We found that the mean length of hospital stay was 47 days, but this finding was contradictory to that of Sayar et al. [23]. Moreover, the mean Waterlow PU score for all participants was $27.19 \pm 13.143$, which suggested very high-PU risk, and this result was consistent with previous studies [23,24]; thus, the Waterlow scoring system was an adequate instrument for risk assessment. The majority of patients included in the study had second-degree PUs (165 patients, 60.7\%). However, higher grades and more severe injury to pressure were seen in another study, including grades 3 and 4 [25]. Another important finding was that the most common location of a PU in our article was the "back" (35.7\%), followed by the "sacral region" (35.3\%), and this was also observed in a study conducted by Sayar et al. [23]. This finding was explained by the fact that for the majority of patients with the head and trunk raised between 15 and 45 degrees, known as the semi-fowler position, PUs are situated on their back. Therefore, understanding the position most vulnerable to the PU can be of great help in preventing PUs. In our research, multinomial logistic regression analysis revealed 
that increasing age was a major predictive factor for developing higher stages of PU $(p=0.046)$ when it comes to aging as a risk factor for PU. This was consistent with most previous research $[26,27]$. Furthermore, over half of our participants were over 50 years old as most older people tend to have less mobility and movement as well as an increased risk of comorbidities [28]. In our sample, the rate of bedbound cases (unconscious/incapable of changing position/traction) was 52.7\%. Immobilization has a detrimental impact on the body as a whole, which increases the risk of developing a PU [16]. Statistically significant variations in PU and hemoglobin level were observed. Anemia has been shown to have significant implications in PU [29]; however, another study concluded that low hemoglobin level has no effect on the occurrence of PU [30]. Although this present article has reached its target, there are some important limitations. The study's main limitation was the unreliable, vague, contradictory, and/or incomplete details in the medical records. This could be explained by the lack of continuity that potentially had an indirect effect on follow-up and clinical treatment in the reporting process. Another drawback was that the data did not specify whether the PU was sustained in the hospital or community as well as the exact site of the PU. Moreover, the sample was collected from a single medical institution. Therefore, we suggest prospective studies with a larger sample size to analyze all variables in compliance with the Waterlow parameters and their relationships.

\section{Conclusions}

This retrospective study of patient pressure injury medical records found that major surgery, limited mobility, neurological impairment, low hemoglobin level, inadequate oral nutrition, and older age are factors and good predictors for the occurrence of higher pressure injury levels. According to the results of our single-centered study, healthcare contributors should consider these risks when applying a comprehensive pressure injury management plan.

\section{Additional Information \\ Disclosures}

Human subjects: All authors have confirmed that this study did not involve human participants or tissue. Animal subjects: All authors have confirmed that this study did not involve animal subjects or tissue. Conflicts of interest: In compliance with the ICMJE uniform disclosure form, all authors declare the following: Payment/services info: All authors have declared that no financial support was received from any organization for the submitted work. Financial relationships: All authors have declared that they have no financial relationships at present or within the previous three years with any organizations that might have an interest in the submitted work. Other relationships: All authors have declared that there are no other relationships or activities that could appear to have influenced the submitted work.

\section{References}

1. Kaltenthaler E, Withfield MD, Walters SJ, Akehurst RL, Paisley S: UK, USA and Canada: how do their pressure ulcer prevalence and incidence data compare?. J Wound Care. 2001, 10:530-5. 10.12968/jowc.2001.10.1.26039

2. Prevention and treatment of pressure ulcers: clinical practice guideline . (2016). Accessed: December 09, 2020: http://epuap.org/wp-content/uploads/2016/10/quick-reference-guide-digital-npuap-epuap-pppiajan2016.pdf.

3. Saleh M, Anthony D, Parboteeah S: The impact of pressure ulcer risk assessment on patient outcomes among hospitalised patients. J Clin Nurs. 2009, 18:1923-9. 10.1111/j.1365-2702.2008.02717.x

4. Tubaishat A, Anthony D, Saleh M: Pressure ulcers in Jordan: a point prevalence study . J Tissue Viability. 2011, 20:14-9. 10.1016/j.jtv.2010.08.001

5. Al-Otaibi YK, Al-Nowaiser N, Rahman A: Reducing hospital-acquired pressure injuries. BMJ Open Qual. 2019, 8:e000464. 10.1136/bmjoq-2018-000464

6. Tescher AN, Branda ME, Byrne TJ, Naessens JM: All at-risk patients are not created equal: analysis of Braden pressure ulcer risk score to identify specifics risks. J Wound Ostomy Continence Nurs. 2012, 39:282-91. 10.1097/WON.0b013e3182435715

7. Oliveira AC, Sabino CP, Almeida AD, Santos AC: Úlcera por presión: incidencia y factores demográficos, clínicos y nutricionales asociados en pacientes de una unidad de cuidados intensivos. Nutr Hosp. 2015, 32:2242-52. 10.3305/nh.2015.32.5.9646

8. Preventing pressure ulcers in hospitals . (2014). Accessed: October 15, 2020: http://www.ahrq.gov/professionals/systems/hospital/pressureulcertoolkit/putool1.html.

9. Demarré L, Van Lancker A, Van Hecke A, et al.: The cost of prevention and treatment of pressure ulcers: a systematic review. Int J Nurs Stud. 2015, 52:1754-74. 10.1016/j.ijnurstu.2015.06.006

10. Sumarno AS: Pressure ulcers: the core, care and cure approach. Br J Community Nurs. 2019, 24:38-42. 10.12968/bjcn.2019.24.Sup12.S38

11. Edlich RF, Winters KL, Woodard CR, Buschbacher RM, Long WB, Gebhart JH, Ma EK: Pressure ulcer prevention. J Long Term Eff Med Implants. 2004, 14:285-304. 10.1615/jlongtermeffmedimplants.v14.i4.20

12. Roaf R: The causation and prevention of bed sores . J Tissue Viability. 2006, 16:6-8. 10.1016/s0965206x(06)62002-0

13. Jaul E: Assessment and management of pressure ulcers in the elderly: current strategies . Drugs Aging. 2010, 27:311-25. 10.2165/11318340-000000000-00000

14. Lindgren M, Unosson M, Fredrikson M, Ek AC: Immobility - a major risk factor for development of pressure ulcers among adult hospitalized patients: a prospective study. Scand J Caring Sci. 2004, 18:57-64. 10.1046/j.0283-9318.2003.00250.x 
15. Ek AC: Prediction of pressure sore development . Scand J Caring Sci. 1987, 1:77-84. 10.1111/j.14716712.1987.tb00603.x

16. Allman RM, Goode PS, Patrick MM, Burst N, Bartolucci AA: Pressure ulcer risk factors among hospitalized patients with activity limitations. JAMA. 1995, 11:865-70. 10.1001/jama.1995.03520350047027

17. Coleman S, Gorecki C, Nelson EA, et al.: Patient risk factors for pressure ulcer development: systematic review. Int J Nurs Stud. 2013, 1:974-1003. 10.1016/j.ijnurstu.2012.11.019

18. Kemp MG, Keithley JK, Smith DW, Morreale B: Factors that contribute to pressure sores in surgical patients . Res Nurs Health. 1990, 13:293-301. 10.1002/nur.4770130505

19. Ek AC, Unosson M, Larsson J, Von Schenck H, Bjurulf P: The development and healing of pressure sores related to the nutritional state. Clin Nutr. 1991, 10:245-50. 10.1016/0261-5614(91)90002-t

20. Theaker C: Pressure prevention in the critically ill: what you don't know, what you should know and why it's important. Intensive Crit Care Nurs. 2003, 19:163-8. 10.1016/S0964-3397(03)00025-9

21. Spruce L: Back to basics: preventing perioperative pressure injuries. AORN J. 2017, 105:92-9. 10.1016/j.aorn.2016.10.018

22. Mervis JS, Phillips TJ: Pressure ulcers: pathophysiology, epidemiology, risk factors, and presentation . J Am Acad Dermatol. 2019, 81:881-90. 10.1016/j.jaad.2018.12.069

23. Sayar S, Turgut S, Doğan H, et al.: Incidence of pressure ulcers in intensive care unit patients at risk according to the Waterlow scale and factors influencing the development of pressure ulcers. J Clin Nurs. 2009, 18:765-74. 10.1111/j.1365-2702.2008.02598.x

24. Boyle M, Green M: Pressure sores in intensive care: defining their incidence and associated factors and assessing the utility of two pressure sore risk assessment tools. Aust Crit Care. 2001, 14:24-30. 10.1016/S1036-7314(01)80019-9

25. Clark M, Cullum N: Matching patient need for pressure sore prevention with the supply of pressure redistributing mattresses. J Adv Nurs. 1992, 17:310-6. 10.1111/j.1365-2648.1992.tb01909.x

26. Burd C, Langemo DK, Olson B, Hanson D, Hunter S, Savage T: Epidemiology of pressure ulcers in a skilled care facility. J Gerontol Nurs. 1992, 18:29-39.

27. Gosnell DJ, Johannsen J, Ayres M: Pressure ulcer incidence and severity in a community hospital . Decubitus. 1992, 5:62.

28. Braden B, Bergstrom N: A conceptual schema for the study of the etiology of pressure sores . Rehabil Nurs. 1987, 12: 8-12. 10.1002/j.2048-7940.1987.tb00541.x

29. Williams DF, Stotts NA, Nelson K: Patients with existing pressure ulcers admitted to acute care. J Wound Ostomy Continence Nurs. 2000, 27:216-26. 10.1067/mjw.2000.107875

30. Phillips LB: Pressure ulcers - prevention and treatment guidelines. Nurs Stand. 1999, 14:56-8. 10.7748/ns.14.12.56.s48 